\section{Case Reports in Neurology}

$10.1159 / 000496536$

C) 2019 The Author(s)

Published by S. Karger AG, Basel www.karger.com/crn

This article is licensed under the Creative Commons Attribution-NonCommercial 4.0 International License (CC BY-NC) (http://www.karger.com/Services/OpenAccessLicense). Usage and distribution for commercial purposes requires written permission.

\title{
An Outbreak of Peripheral Neuropathy in a Prison
}

\author{
Somsak Tiamkao ${ }^{a} \quad$ Anuwat Boonsong $^{a} \quad K^{2}$ amol Saepeung \\ Narongrit Kasemsap ${ }^{a} \quad$ Metha Apiwattanakul $^{c} \quad$ Narupat Suanprasert $^{c}$ \\ Thiravat Hemachudhad ${ }^{d}$ Prakai Pithak $^{e}$ Kittiphit Juntee ${ }^{f}$ \\ Chamnan Waisaen $^{g}$ Supat Madha ${ }^{\mathrm{h}}$ Rome Buathong ${ }^{\mathrm{i}}$ \\ Kittisak Sawanyawisuth
}

aDivision of Neurology, Department of Medicine, Faculty of Medicine, and Integrated Epilepsy Research Group, Khon Kaen University, Khon Kaen, Thailand; 'bueng Kan Hospital, Bueng Kan, Thailand; 'Prasat Neurological Institute, Bangkok, Thailand; dDivision of Neurology, Department of Medicine, Faculty of Medicine, Chulalongkorn University, Bangkok, Thailand; eEpidemiology of Communicable Disease Unit, Srinagarind Hospital, Faculty of Medicine, Khon Kaen University, Khon Kaen, Thailand; ${ }^{\text {OOffice of }}$ Disease Prevention and Control Region 6, Khon Kaen, Thailand; 'Bueng Kan Provincial Health Office, Bueng Kan, Thailand; hBueng Kan Provincial Prison, Bueng Kan, Thailand; 'Bureau of Epidemiology, Department of Disease Control, Ministry of Public Health, Bangkok, Thailand; jDivision of Ambulatory Medicine, Department of Medicine, Faculty of Medicine, Sleep Apnea Research Group, Research Center in Back, Neck, and Other Joint Pain and Human Performance, Research and Training Center for Enhancing Quality of Life of Working Age People, and Research and Diagnostic Center for Emerging Infectious Diseases, Khon Kaen University, Khon Kaen, Thailand

\section{Keywords}

Thiamine $\cdot$ Arsenic $\cdot$ Rhinovirus $\cdot$ Mycoplasma 


\section{Case Reports in Neurology}

\begin{abstract}
Prisoners are at risk for both physical and psychological diseases. Here, we report an outbreak of peripheral neuropathy in a prison in northeast Thailand. Between July and December 2014, there were 88 male prisoners at Bueng Kan Provincial Prison in Bueng Kan, Thailand suffering from peripheral neuropathy out of a total of 1,464 prisoners (6.01\%). The common age range was $20-39$ years (58 patients; $65.91 \%$ ). The three most common features were hyporeflexia/ areflexia of the lower extremities (36 patients; 83.72\%). On laboratory vitamin B1 deficiency was detected in $4 / 5$ patients, positive rhinovirus polymerase chain reaction in $3 / 4$ patients, positive Mycoplasma pneumoniae IgM in $1 / 12$ patients, and positive urinary arsenic in 4/7 patients. A dT vaccination was given on October 14 during the outbreak. This was a large outbreak of peripheral neuropathy in male prisoners. There are several possible causes of this outbreak including vitamin B1 deficiency, dT vaccination, arsenic toxicity, rhinovirus, and Mycoplasma infection.

(C) 2019 The Author(s)

Published by S. Karger AG, Basel
\end{abstract}

\title{
Introduction
}

Prisoners are at risk for both physical and psychological diseases such as hepatitis $C$ virus infection, tuberculosis, and depression [1-3]. A study in Germany found epilepsy and peripheral nerve lesions to be the two most common neurological diseases among prisoners there [4]. Another report found that 679 out of 4,684 (14.5\%) ex-Far Eastern prisoners of war suffered from neurological disease, optic atrophy, and peripheral neuropathy. In addition, it has been found that Parkinson's disease may develop at a higher prevalence than in the general population, even several years after release [5].

In December, 2014, there was an outbreak of peripheral neuropathy at Bueng Kan Provincial Prison, located in Bueng Kan province in northeast Thailand. Twenty-nine prisoners were reported to suffer from muscle weakness in both legs and numbness in the hands and feet. There are several possible causes of peripheral neuropathy including vitamin B1 deficiency, vaccination, infections, or toxins such as arsenic [6-9]. Prisoners are a vulnerable population and at are risk for nutritional deficiency. Additionally, a few months prior to the outbreak, there was an outbreak of diphtheria all over Thailand. Thus, all prisoners had received diphtheria and tetanus vaccinations prior to the outbreak. A previous study showed that peripheral neuropathy in prisoners at a Bangkok Central Prison had been due to arsenic-contaminated water [8]. This study aimed to evaluate the prevalence and causes of the peripheral neuropathy outbreak at this provincial prison.

\section{Methods}

This study was conducted at Bueng Kan Provincial Prison in Bueng Kan, Thailand. The inclusion criteria were that subjects had experienced weakness or paresthesia between July and December 2014. The clinical diagnosis of peripheral neuropathy was made based on the presence of one or more of the following: weakness of the arms and/or legs, paresthesia of 


\section{Case Reports in Neurology}

any part of the body, autonomic symptoms such as constipation, urinary incontinence, or erectile dysfunction. Electromyography was used as a confirmatory test.

Laboratory workups were performed on both symptomatic and asymptomatic subjects, at the subjects' voluntary discretion. These workups aimed to find possible causes of peripheral neuropathy, such as viral infection or toxic substances, and included a throat swab, a rectal swab, a blood sample, a urine sample, a cerebrospinal fluid sample, and a measurement of vitamin B1 levels. All workups were analyzed at the Department of Laboratory Medicine at Bangkok's Chulalongkorn Hospital. An environmental survey was also performed to evaluate the sanitary conditions of the prison, the environment, and the prisoners' nutritional/food data.

\section{Results}

There were 88 male patients who were diagnosed as suffering from peripheral neuropathy out of a total of 1,464 prisoners (6.01\%). The common age range was 20-39 years (58 patients; 65.91\%). Most patients (59 patients; 67.04\%) lived in sleeping units 5 and 6 (Table 1). The three most common features were hyporeflexia/areflexia of the lower extremities (36 patients; $83.72 \%$ ), sensory deficit (34 patients; $78.81 \%$ ), and motor weakness (31 patients; $72.09 \%$ ), as shown in Table 2.

The laboratory workups found various abnormalities in prisoners suffering from peripheral neuropathy. According to electromyography results, 5 out of 6 patients (83\%) had sensorimotor axonal polyneuropathy. Vitamin B1 levels were low in 4 out of 5 male prisoners with peripheral neuropathy, while only 2 out of 5 male prisoners without peripheral neuropathy had low vitamin B1 levels (Table 3). Other workup results showed that $75 \%$ of prisoners with peripheral neuropathy were positive for rhinovirus (according to a throat swab), 8\% were positive for Mycoplasma pneumoniae IgM, and 57\% had high urinary arsenic levels (Table 3).

The first peripheral neuropathy patient was reported on July 4, 2014. Later, there were two peaks of patients being reported, one in the week of September 28 to October 4 and the other in the week of November 11-15, with a higher number of patients being reported in the latter period. There was a total of 41 patients diagnosed in November. The dT vaccination was given on October 14 (Fig. 1).

Various environmental aspects of the prison were also taken into account. There are a total of 1,464 prisoners in the prison, 1,285 of whom are male and 133 of whom are female. The interior space of the prison has the capacity to hold 1,350 prisoners. There are six sleeping units with a total capacity of 571 . Water for general use is ground water without standard water chlorination, while filtered tap water is used for drinking. With regard to food, breakfast and dinner consist of sticky rice with one side dish and lunch consists of a rice dish. Fruits are occasionally served. Meals provided for the prisoners contain between 0.70 and $2.03 \mathrm{mg}$ of vitamin B1 per day, or $1.35 \mathrm{mg}$ on average. 


\section{Case Reports in Neurology}

\section{Discussion}

This was a large outbreak of peripheral neuropathy in male prisoners. There are several possible causes of this outbreak including vitamin B1 deficiency, dT vaccination, arsenic toxicity, rhinovirus, and Mycoplasma infection (Table 3).

Vitamin B1 is a common cause of peripheral neuropathy in prisoners or ex-prisoners of war. Peripheral neuropathy without cardiac involvement may be the only clinical manifestation apparent in an outbreak, as was the case in this study [10]. A report from Cuba found that sensory deficit was the most common symptom (78.95\%), the reported rate of which was comparable to that found in this study (78.81\%). Although hyporeflexia was the most common finding (83.72\%), it is a physical sign, not a symptom that patients complain about (Table 1). The low vitamin B1 levels in prisoners and prison diets being low in vitamin B1containing foods act as supportive evidence for vitamin B1 deficiency as a cause of the outbreak. The percentage of male prisoners with vitamin B1 deficiency was higher than that of normal male prisoners ( 80 vs. $40 \%$ ), as shown in Table 3. Though the average amount of vitamin B1 in meals served at the prison was higher than the recommended requirements (1.35 mg vs. $1.2 \mathrm{mg}$ for males), vitamin B1 deficiency may occur due to low meat intake or to meals being served with white rice as opposed to other types. Polished or white rice contains lower amounts of vitamin B1 than brown rice. As has previously been reported, males are typically predominant in prison settings, in which the male:female ratio can be as high as 18:1 [11]. In addition, populations from northeast Thailand tend to have lower vitamin B1 levels than those from other parts of the country [12]. Up to 88\% of laborers from the northeast were found to suffer from thiamine deficiency [12]. Vitamin B1 deficiency may not explain all aspects of this outbreak, such as the two peaks in the number of reported cases, as shown in Figure 1. There may, thus, be other contributing causes of this outbreak.

Rhinovirus may be another contributing factor. Between 20 and $75 \%$ of the laboratory tests in this study were positive for rhinovirus (Table 3). Two previous reports showed that enterovirus may be associated with neuropathy $[13,14]$. For example, polio-like acute flaccid paralysis was found to be followed by an enterovirus D68 outbreak in Cleveland, USA [13]. It has also been shown that neural degeneration or dysfunction may occur due to cough-induced plasticity in the neural pathways [14]. Additionally, crowded sleeping units may be an aggravating factor for viral infection and other infectious agents such as Mycoplasma or tuberculosis $[15,16]$. There have been reports of outbreaks of adenovirus serotype $14 \mathrm{p} 1$ and an influenza A/Fujian/411/2002 (H3N2)-like virus in prisons in the UK and Australia. Even though M. pneumoniae may be associated with acute motor axonal neuropathy [17], the evidence for acute M. pneumoniae as a cause of the outbreak in this survey was low (8\%), as shown in Table 3.

Diphtheria and tetanus vaccines have been shown to be associated with neuropathy and Guillain-Barré syndrome $[6,18]$. These vaccinations cannot explain the first peak of this outbreak (Fig. 1), which occurred prior to the mass dT vaccination on October 14. However, it may have been a contributing factor in the second peak.

There are some limitations to this study. First, not all patients were given all laboratory workups, as these were performed on a voluntary basis. Second, the amounts of vitamin B1 provided in meals was calculated based on estimates, not actual measurement. Finally, other possible causes of neuropathy were not fully investigated, such as hepatitis or HIV infection. 


\section{Conclusion}

There are several possible contributing factors to the peripheral neuropathy outbreak in the prison. Vitamin B1 deficiency is a potential and treatable cause. Further evaluations of the prisoners may be needed.

\section{Acknowledgments}

This study was conducted through collaboration and funding/material support from: (1) The Department of Medical Sciences, Ministry of Public Health, Thailand. (2) The work on viral study at Chulalongkorn Laboratory was supported in part by the "Research Chair Grant" National Science and Technology Development Agency (NSTDA), Thailand. (3) Bueng Kan Hospital, Bueng Kan, Thailand. (4) Faculty of Medicine, Khon Kaen University, Khon Kaen. (5) Office of Disease Prevention and Control Region 6, Khon Kaen. (6) Regional Medical Sciences Center 8, Udon Thani. (7) Bureau of Epidemiology, Department of Disease Control, Ministry of Public Health, Thailand. (8) Officials at Bueng Kan Provincial Prison, Bueng Kan, Thailand.

\section{Statement of Ethics}

The authors have no ethical conflicts to disclose.

\section{Disclosure Statement}

The authors declare no conflicts of interest.

\section{References}

1 Hodžić H, Bajramović A, Obradović Z, Mahmić-Kaknjo M. Intravenous drugs abuse as the main risk factor of increasing hepatitis $\mathrm{C}$ infection prevalence in prisoners in Zenica, Bosnia and Herzegovina. Med Glas (Zenica). 2017 Feb;14(1):73-8.

2 Nunes C, Duarte R, Veiga AM, Taylor B. Who are the patients that default tuberculosis treatment? - space matters! Epidemiol Infect. 2017 Apr;145(6):1130-4.

3 O'Hara K, Forsyth K, Webb R, Senior J, Hayes AJ, Challis D, et al. Links between depressive symptoms and unmet health and social care needs among older prisoners. Age Ageing. 2016 Jan;45(1):158-63.

4 Kallert TW. Duties of a psychiatric-neurological consultation/liaison service in a prison setting. Forensic Sci Int. 1996 Aug;81(2-3):103-16.

5 Gibberd FB, Simmonds JP. Neurological disease in ex-Far-East prisoners of war. Lancet. 1980 Jul;2(8186): 135-7.

6 Kongbunkiat K, Kasemsap N, Tiamkao S, Sawanyawisuth K. Clinical manifestations and outcomes of GuillainBarré syndrome after diphtheria and tetanus vaccine (dT) during a diphtheria outbreak in Thailand: a Case series. Neurol Asia. 2014;19:137-55.

7 Doung-ngern P, Kesornsukhon S, Kanlayanaphotporn J, Wanadurongwan S, Songchitsomboon S. Beriberi outbreak among commercial fishermen, Thailand 2005. Southeast Asian J Trop Med Public Health. 2007 Jan;38(1):130-5. 
8 Voradetwittaya L, Sirikanoke I, Ieowongjaroen I, Karnjanapiboonwong A, Buathong R. Flood-related outbreak of peripheral neuropathy among prisoners in Bangkok, Thailand. Outbreak Surveill Investig Rep. 2014 Mar;7(1):1-8.

9 Makonahalli R, Seneviratne J, Seneviratne U. Acute small fiber neuropathy following Mycoplasma infection: a rare variant of Guillain-Barré syndrome. J Clin Neuromuscul Dis. 2014 Jun;15(4):147-51.

10 Lincoff NS, Odel JG, Hirano M. "Outbreak" of optic and peripheral neuropathy in Cuba? JAMA. 1993 Jul;270(4):511-8.

11 Cissé FA, Konaté MM, Ekué WA, Cissé M, Camara N, Djigué BS, et al. [Clinical appearance and scalable profile Thiamine deficiency in prison in Guinea: study of thirty-eight observations]. Bull Soc Pathol Exot. 2016 May;109(2):70-6.

12 Songchitsomboon S, Kulapongse S, Likittanasombat K, Puchaiwatananon O, Sakulsangprapa T, Sritara P. Thiamin and riboflavin status in North-eastern Thai workers. Rama Med J. 1993;16:317-22.

13 Foster CB, Friedman N, Carl J, Piedimonte G. Enterovirus D68: a clinically important respiratory enterovirus. Cleve Clin J Med. 2015 Jan;82(1):26-31.

14 Undem BJ, Zaccone E, McGarvey L, Mazzone SB. Neural dysfunction following respiratory viral infection as a cause of chronic cough hypersensitivity. Pulm Pharmacol Ther. 2015 Aug;33:52-6.

15 Parcell BJ, McIntyre PG, Yirrell DL, Fraser A, Quinn M, Templeton K, et al. Prison and community outbreak of severe respiratory infection due to adenovirus type 14p1 in Tayside, UK. J Public Health (Oxf). 2015 Mar;37(1):64-9.

16 Young LC, Dwyer DE, Harris M, Guse Z, Noel V, Levy MH; Prison Influenza Outbreak Investigation Team. Summer outbreak of respiratory disease in an Australian prison due to an influenza A/Fujian/411/ 2002(H3N2)-like virus. Epidemiol Infect. 2005 Feb;133(1):107-12.

17 Rajabally YA, Sarasamma P. Anti-GM1 antibody-negative acute motor axonal neuropathy after Mycoplasma pneumoniae infection. Eur J Neurol. 2006 Jan;13(1):95-6.

18 Pollard JD, Selby G. Relapsing neuropathy due to tetanus toxoid. Report of a case. J Neurol Sci. 1978 Jun;37(1-2):113-25.

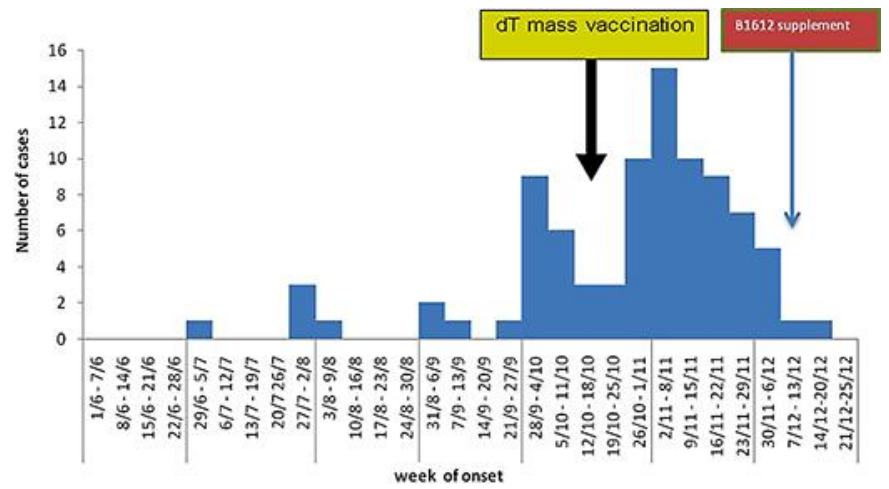

Fig. 1. Epidemic curve in Bueng Kan Prison, Bueng Kan province, Thailand. December 2014: $n=88$. 
Table 1. Baseline characteristics of patients with peripheral neuropathy during the outbreak

\begin{tabular}{lc}
\hline Variables & $n(\%)$ \\
\hline Sex & \\
$\quad$ Male & $88(100)$ \\
Age, years & \\
$10-19$ & $1(1.14)$ \\
$20-29$ & $30(34.09)$ \\
$30-39$ & $28(31.82)$ \\
$40-49$ & $16(18.18)$ \\
$50-59$ & $10(11.36)$ \\
60 and over & $3(3.41)$ \\
Sleeping unit & $5(5.68)$ \\
1 & $9(10.23)$ \\
2 & $9(10.23)$ \\
3 & $4(4.55)$ \\
4 & $30(34.09)$ \\
5 & $29(32.95)$ \\
6 & $2(2.27)$ \\
\hline
\end{tabular}

Table 2. Clinical manifestations of patients with peripheral neuropathy $(n=43)$ during the outbreak

\begin{tabular}{lcc}
\hline Signs and symptoms & $n$ & $\%$ \\
\hline Hyporeflexia/areflexia of lower extremity & 36 & 83.72 \\
Sensory deficit & 34 & 78.81 \\
Motor weakness & 31 & 72.09 \\
Edema of lower extremity & 15 & 34.88 \\
Hyporeflexia/areflexia of upper extremity & 13 & 30.23 \\
Erectile dysfunction & 5 & 11.62 \\
Constipation & 4 & 9.30 \\
Dysphagia & 3 & 6.98 \\
Leg cramp & 2 & 4.65 \\
Urinary retention & 1 & 2.32 \\
\hline
\end{tabular}


Table 3. Laboratory findings of patients with/without peripheral polyneuropathy during the outbreak

\begin{tabular}{|c|c|c|c|}
\hline Specimens/tests & Variables & Tested, $n$ & Positive, $n(\%)$ \\
\hline \multirow[t]{3}{*}{ Throat swab } & Respiratory viruses 16 type PCRa & 4 & $3(75 \%)^{a}$ \\
\hline & Mycoplasma pneumoniae & 7 & $7(100 \%)$ \\
\hline & Enterovirus $\mathrm{PCR}^{\mathrm{b}}$ & 10 & $2(20 \%)^{a}$ \\
\hline \multirow[t]{3}{*}{ Serum } & Herpes simplex IgM & 12 & $2(17 \%)$ \\
\hline & Mycoplasma pneumoniae IgM & 12 & $1(8 \%)$ \\
\hline & Mycoplasma pneumoniae IgG & 12 & $8(67 \%)$ \\
\hline Blood & Lead & 7 & 0 \\
\hline Urine & Arsenic & 7 & $4(57 \%)$ \\
\hline Stool & Rhinovirus PCR & 10 & $2(20 \%)$ \\
\hline \multirow[t]{4}{*}{ Vitamin $\mathrm{B} 1^{\mathrm{c}}$} & Male patients (prisoners) & 5 & $4(80 \%)$ \\
\hline & Normal male prisoners & 5 & $2(40 \%)$ \\
\hline & Normal female prisoners & 5 & $4(80 \%)$ \\
\hline & Normal wardens & 5 & $4(80 \%)$ \\
\hline Electromyogram & Sensorimotor axonal polyneuropathy & 6 & $5(83 \%)$ \\
\hline MRI & Brain, spinal cord & 2 & 0 \\
\hline
\end{tabular}

MRI, magnetic resonance imaging; PCR, polymerase chain reaction. a Positive for rhinovirus. ${ }^{b}$ Enteroviruses family PCR for genetic locations: VP3/1, VP4/2, and 5'UTR long covering poliovirus (human enterovirus C serotypes PV-1, PV-2, PV-3), human coxsackievirus, human enterovirus 70 (EV-70), EV-71, and human rhinovirus A, but not Picornaviridae. c Vitamin B1 level tested by high-performance liquid chromatography and erythrocyte transketolase activity. 